\title{
CORRECTION
}

\section{Correction to: Determination of the Genetic and Synergistic Suppression of a Methoxyfenozide-Resistant Strain of the House Fly Musca domestica L. (Diptera: Muscidae)}

\author{
RM ShaH ${ }^{1}$, N ABbas ${ }^{1,2}$, SA SHAD ${ }^{1}$, M BINYAMEEN $^{1,3,4}$ \\ ${ }^{1}$ Dept of Entomology, Faculty of Agricultural Sciences and Technology, Bahauddin Zakariya Univ, Multan, Pakistan \\ ${ }^{2}$ Dept of Entomology, Univ College of Agriculture and Environmental Sciences, The Islamia Univ of Bahawalpur, Bahawalpur, Pakistan \\ ${ }^{3}$ Faculty of Forestry and Wood Sciences, EXTEMIT-K, Czech Univ of Life Sciences, Suchdol, Czech Republic \\ ${ }^{4}$ Department of Entomology, Chemical Ecology Laboratory, Penn State University, University Park, PA, USA
}

\section{Correction to: Neotrop Entomol}

https://doi.org/10.1007/s13744-018-0604-9

Due to an unfortunate turn of events, the surname of the last author appeared incorrectly in the original publication as the name should have read Binyameen.

The correct representation of the authors' names and their affiliation is listed here and should be treated as definitive. We apologize to authors and readers for the inconvenience. 